DOI: 10.12957/demetra.2017.22877

\title{
Manual de Boas Práticas para Bancos de Alimentos: a perspectiva de uma nova construção
}

\author{
Manual of Good Practices for Food Banks: the perspective of a new construction
}

\author{
Natália Ferreira de Paula' \\ Luana de Assis ${ }^{2}$ \\ Cilene da Silva Gomes Ribeiro ${ }^{3}$ \\ Islandia Bezerral \\ 1 Universidade Federal do Paraná, Departamento \\ de Nutrição, Programa de Pós-graduação em \\ Alimentação e Nutrição. Curitiba-PR, Brasil. \\ 2 Pontifícia Universidade Católica do Paraná, \\ Programa de Pós-graduação em Bioética. \\ Curitiba-PR, Brasil. \\ ${ }^{3}$ Pontifícia Universidade Católica do Paraná, \\ Curso de Nutrição. Curitiba-PR, Brasil. \\ Correspondência / Correspondence \\ Natália Ferreira de Paula \\ E-mail: nataliafesr13@gmail.com
}

\section{Resumo}

Os Bancos de Alimentos (BA) são os Equipamentos de Segurança Alimentar e Nutricional (SAN) mais importantes para o combate ao desperdício de alimentos em todo o país. Atualmente, existem 214 BA em operacionalização no Brasil. Os alimentos recebidos pelos Bancos frequentemente não possuem valor comercial, no entanto, encontram-se próprios para o consumo. As Boas Práticas, por sua vez, tornam-se elementos essenciais para garantir a qualidade dos produtos recebidos e doados pelos BA. O Manual de Boas Práticas (MBP) norteia a implantação das Boas Práticas e auxilia na sua manutenção. Considerando a importância do MBP para a promoção da SAN dos beneficiários receptores, assim como a inexistência de literatura específica para o setor, o presente artigo objetivou apresentar uma proposta de Roteiro de MBP com olhar ampliado para aplicação nos BA. A sistematização da proposta segue uma adaptação de MBP utilizado para serviços de alimentação e marcos normativos referentes às Boas Práticas em âmbito nacional e internacional. O Roteiro foi composto por dez itens, que são detalhados, relacionados com os marcos normativos, e abordam, além dos controles de qualidade normalmente observados para os serviços de alimentação, artigos peculiares aos BA. Por fim, é importante destacar que o MBP deve ser desenvolvido de acordo com cada realidade. Ressalta-se ainda que o roteiro por si só não promove a SAN dos beneficiários receptores, pois existe a necessidade de executar sistematicamente o que está descrito e/ou realizar adaptações para garantir o controle de qualidade dos alimentos.

Palavras-chave: Segurança Alimentar e Nutricional. Controle de Qualidade. Qualidade dos Alimentos. Manuais. 


\section{Abstract}

Food Banks (FB) are the most important Food and Nutrition Security (FNS) Equipments to fight against food waste all over the country. There are currently 214 FBs in operation in Brazil. The food received by the Banks usually have no commercial value, however it's adequate for consumption. The Good Practices, on the other hand, become essential elements to guarantee the quality of the received and donated food by the FBs. The Manual of Good Practices (MGP) guides the implementation of the Good Practices and helps its maintenance. Considering the importance of the MGP for the promotion of the FNS of the FBs beneficiary receivers, as well as the lack of specific literature for the sector, the present article presents a script proposition of MGP with an look enlarged for application in the FBs. as the inexistence of specific material for the available sectors in literature, for the FBs. The systematization of the proposal follows an adaptation of the MGP used for food services and normative marks referring to Good Practices in national and international range. The Script was made of ten items, which are detailed, related to the normative marks and they approach, besides the quality control observed for the food services, peculiar items to the FBs. Finally, it is important to highlight that the MGP should be developed according to each reality. It is also worth noting that the road map alone does not promote the FNS of the beneficiary receiver, as there is a need to systematically implement what is described and/or to make adaptations to ensure the quality control of food.

Keywords: Food and Nutrition Security. Quality Control. Food Quality. Handbooks.

\section{Introdução}

Por Segurança Alimentar e Nutricional (SAN) entende-se a realização do direito de todos ao acesso regular e permanente a alimentos de qualidade, em quantidade suficiente, sem comprometer o acesso a outras necessidades essenciais, tendo como base práticas alimentares promotoras de saúde que respeitem a diversidade cultural e que sejam ambiental, cultural, econômica e socialmente sustentáveis. ${ }^{1}$

Entre os inúmeros critérios que se preconizam para que seja alcançada a SAN, um dos mais discutidos na ciência da nutrição é o da qualidade dos alimentos. Existem diversas definições para que um alimento seja de qualidade, algumas mais restritas e outras mais abrangentes, e aqui utilizaremos como parâmetro a definição de qualidade ampla dos alimentos, na qual os 
fatores considerados para a qualidade englobam os aspectos regulamentar, sanitário, ecológico, organoléptico, nutricional, social, cultural, facilidade de uso e aparência. ${ }^{2}$

Uma vez contemplados os conceitos, acredita-se esclarecer que a qualidade do alimento ou a SAN são compostas por inúmeros aspectos e que, ao explorar um deles, no caso deste trabalho, o critério de "alimento de qualidade", no que se refere à SAN, $e$ o "aspecto sanitário", inerente à qualidade ampla, não estaremos atingindo na íntegra a qualidade do alimento ou a SAN dos consumidores, mas, sim, caminhando para sua efetivação.

Isto posto, partimos para o recorte do aspecto sanitário e/ou higiênico da qualidade do alimento, que objetiva garantir ao consumidor que o alimento ingerido seja adequado e seguro. ${ }^{2}$ Para que possa ser atribuído este aspecto da qualidade, faz-se necessária a aplicação de princípios gerais que garantam a higiene dos alimentos, bem como aperfeiçoamento constante dessas ações. ${ }^{3}$

O Alimento Seguro nos Bancos de Alimentos em prol da SAN

Ainda que exista uma definição restrita sobre qualidade de alimentos, contrapondo à qualidade ampla, o Codex Alimentarius ${ }^{4}$ é, certamente, uma importante referência para o campo do alimento seguro. Segundo esta normativa, a aplicação dos princípios gerais e de Boas Práticas de Fabricação (BPF) permite condições ambientais favoráveis para a produção de alimentos seguros.

Contudo, vale salientar que a execução das BPF é normatizada através de legislações nacionais e internacionais, que estabelecem necessidades mínimas a ser tomadas pelos serviços de alimentação.

Os normativos de BPF são instituídos no Brasil pelo Ministério da Saúde (MS) - Vigilância Sanitária e pelo Ministério da Agricultura, Pecuária e Abastecimento (MAPA), e usualmente, por conta de seu objeto, funcionam muito próximos de uma lógica de mercado que exclui outras estratégias de produção e comercialização e prioriza, fundamentalmente, o lucro. Além disso, pautam-se no que determinam as grandes indústrias e outros segmentos do comércio de bens e serviços do setor, sendo, assim, pressionados para estabelecerem determinados padrões, já que estes são suas demandas. ${ }^{5}$ Dessa forma, a legislação sanitária federal mantém padrões de qualidade homogeneizados e baseados na produção de larga escala, que necessitam de altos investimentos para sua aplicação..$^{5,6}$

Alguns setores da área da alimentação não possuem legislações de Boas Práticas específicas, como é o caso dos Bancos de Alimentos (BA). Desse modo, o Manual de Boas Práticas (MBP) configura-se um documento que descreve e reúne as BPF instituídas para determinado estabelecimento, por este motivo pode, se implantado e implementado corretamente, contribuir para o controle higiênico sanitário dos alimentos., ${ }^{7,8}$

Existem na bibliografia diversos roteiros para elaboração do MBP, voltados para Serviços de Alimentação e Nutrição e para indústrias de alimentos. Nesse contexto, pode-se citar o Roteiro para elaboração do MBP para Indústrias de Alimentos e para Serviços de Alimentação, da Vigilância 
e Fiscalização Sanitária do Município do Rio de Janeiro, ${ }^{9}$ o Guia de Elaboração do MBP para Manipulação de Alimentos, do Conselho Regional de Nutricionistas $4^{\mathrm{a}}$ região (CRN-4), ${ }^{10}$ o Modelo Básico de MBP para Orientação dos Profissionais, do Conselho Regional de Nutricionistas 3aㅡ região (CRN-3), ${ }^{11}$ entre outros.

Porém, a bibliografia específica para elaboração do MBP para os BA ainda é restrita, sobretudo, considerando em si a ampliação do olhar no que se refere a "alimentos de qualidade" e à flexibilização das normas sanitárias para esse equipamento descentralizado de SAN. É relevante destacar, ainda, que os BA distinguem-se em inúmeros fatores das indústrias alimentícias, do comércio de bens e serviços e da produção em larga escala, setores estes que "inspiram” a elaboração da legislação sanitária, conforme anteriormente pontuado. ${ }^{5}$

\section{Os Bancos de Alimentos e sua função social}

Os BA são utilizados em diversos países do mundo para auxiliar no combate à (in)segurança alimentar e nutricional da população. ${ }^{12,13}$ Implantados no Brasil há pouco mais de uma década, além de atuar para a promoção da SAN no país, os BA consistem nos mais importantes instrumentos de combate ao desperdício de alimentos. ${ }^{14}$ Atualmente, estão implantados no Brasil 214 BA, sendo 109 Bancos públicos, que são financiados pelo Ministério do Desenvolvimento Social e Combate à Fome (MDS), e outros 105 da iniciativa privada. ${ }^{14}$

Os BA no Brasil são classificados como Equipamentos Descentralizados de Segurança Alimentar e Nutricional (EDSAN) e entre suas atividades estão: coletar, selecionar, processar, armazenar e distribuir gêneros alimentícios arrecadados por meio de doações junto à rede varejista e/ou adquiridos da agricultura familiar por meio de programas governamentais, como o Programa de Aquisição de Alimentos (PAA) e o Programa Nacional de Alimentação Escolar (PNAE).$^{15}$ Os alimentos recebidos pelos BA são distribuídos gratuitamente às entidades da rede socioassistencial, que oferecem alimentação aos beneficiários receptores, pessoas em situação de insegurança alimentar e nutricional, e contribuem para o abastecimento de Restaurantes Populares, Cozinhas Comunitárias e Escolas. ${ }^{14}$

As doações de alimentos são provenientes de diferentes locais. Estes alimentos são, muitas vezes, considerados sem valor comercial, mas ainda mantêm suas características nutricionais, não oferecendo risco ao consumo humano, desde que devidamente manipulados. ${ }^{16}$ Nesse sentido, a aplicação das BPF nos BA são essenciais para garantir a qualidade dos alimentos doados às entidades beneficiárias receptoras, principalmente pelo grau de maturidade das doações recebidas, que comumente chegam aos BA com seus prazos de validades próximos aos seus vencimentos, estando, portanto, mais suscetíveis a contaminações ou à perda da qualidade. 
Um dos fatores relevantes para a implantação e a manutenção das BPF é a presença do Responsável Técnico (RT) capacitado. ${ }^{17}$ Assim sendo, destaca-se que a presença de nutricionista, ou outro profissional da área da alimentação devidamente capacitado para coordenar as ações de BPF em BA, ainda que atualmente não seja exigência, mas recomendação do MDS, é, sobretudo, uma potencialidade para o serviço. ${ }^{14}$

Considerando a relevância dos BA para a materialização da SAN no país, o número destes equipamentos que atualmente estão sendo operacionalizados, a necessidade de controle sanitário dos alimentos, bem como a inexistência de orientativos para elaboração de MBP na literatura para este seguimento específico, o presente trabalho tem como objetivo apresentar uma proposta de roteiro, exclusiva para o setor, com a finalidade de nortear a elaboração do MBP.

Ressalta-se que este artigo foi baseado nas legislações de BPF vigentes, no entanto, é importante esclarecer que a intenção não é reforçar a visão biologicista, inerente à formação de profissionais da saúde, especificamente o nutricionista, mas, sim, garantir uma reflexão sobre tais exigências, levando em conta, assim, a perspectiva da "qualidade ampliada", bem como das especificidades inerentes ao setor dos BA. ${ }^{18}$ A expectativa deste artigo é contribuir para a SAN dos indivíduos institucionalizados - nas entidades que recebem tais alimentos dos BA - e, sobretudo, para que o profissional Responsável Técnico (RT) deste equipamento possa assumir uma postura mais problematizadora e reflexiva, relativizando as exigências que são inviáveis de execução em determinados momentos, incorporando alternativas, pautadas no conhecimento técnico, que melhor se adaptem à situação, sempre priorizando a SAN sob a perspectiva do Direito Humano à Alimentação Adequada/DHAA.

\section{Metodologia}

\section{Os caminhos teórico-práticos percorridos}

A metodologia do trabalho foi dividida em três etapas. A primeira foi a identificação e análise de processos comumente executados pelos responsáveis técnicos dos BA. Para tanto, foi realizada análise ${ }^{a}$ do Check List do BA do Programa Mesa Brasil Sesc Paranáb - versão $2013,{ }^{19}$ que é utilizado pela Equipe de Coordenação Estadual do Programa para monitorar as Boas Práticas e outros procedimentos operacionais nas oito unidades do estado. A partir dessa análise, definiu-se os itens pertinentes, a fim de propor um orientativo para elaboração do MBP voltado a este seguimento.

a Para acesso e análise do material, foi realizada solicitação formal ao Sesc PR, que concedeu autorização para o desenvolvimento do trabalho.

b O Mesa Brasil é um Programa do Serviço Social do Comércio (Sesc) de Segurança Alimentar e Nutricional Sustentável, que redistribui alimentos próprios para o consumo às instituições sociais e famílias previamente cadastradas, implantado em âmbito nacional desde o ano de 2003. 
A segunda foi a elaboração de um quadro, contendo os itens que formaram a proposta do roteiro para elaboração do MBP e a relação destes itens com as legislações nacionais e internacionais, visando à sistematização das informações. Para fins de marcos normativos, foram considerados materiais que possuem vigência e aplicação em âmbito federal: a Portaria do Ministério da Saúde (MS) no 1.428, de 26 de novembro de 1993, ${ }^{20}$ a Resolução da Diretoria Colegiada da Agência Nacional de Vigilância Sanitária (ANVISA) no 275, de 21 de outubro de $2002,{ }^{21}$ a RDC da ANVISA nº 216 , de 15 setembro de $2004 .^{22}$

A Portaria MS no 1.428, de 26 de novembro de 1993, aprova, na forma dos textos anexos, o "Regulamento Técnico para Inspeção Sanitária de Alimentos", as "Diretrizes para o Estabelecimento de Boas Práticas de Produção e de Prestação de Serviços na Área de Alimentos" e o "Regulamento Técnico para o Estabelecimento de Padrão de Identidade e Qualidade (PIQs) para Serviços e Produtos na Área de Alimentos". Determina que os estabelecimentos relacionados à área de alimentos adotem, sob responsabilidade técnica, as suas próprias Boas Práticas de Produção e/ ou Prestação de Serviços, seus Programas de Qualidade, e atendam aos PIQs para Produtos e Serviços na Área de Alimentos. ${ }^{20}$

A RDC da ANVISA no 275, de 21 de outubro de 2002, dispõe sobre o "Regulamento Técnico de Procedimentos Operacionais Padronizados aplicados aos Estabelecimentos Produtores/ Industrializadores de Alimentos" e a "Lista de Verificação das Boas Práticas de Fabricação em Estabelecimentos Produtores/ Industrializadores de Alimentos. ${ }^{21}$ A RDC da ANVISA no 216, de 15 setembro de 2004, dispõe sobre "Regulamento Técnico de Boas Práticas para Serviços de Alimentação". 22

Utilizou-se também o Codex Alimentarius na metodologia do trabalho, embora se reconheça as limitações deste para tal aplicação. O Codex é uma norma alimentar adotada internacionalmente, coordenada pela Organização das Nações Unidas para a Alimentação e a Agricultura (FAO) em conjunto com a Organização Mundial da Saúde (OMS), tomada como parâmetro principalmente pela Organização Mundial do Comércio (OMC) para arbitrar ocorrências no âmbito do comércio mundial, onde os alimentos percorrem circuitos longos de comercialização, ${ }^{23}$ situação diferenciada da realidade dos BA, objeto deste trabalho.

Diante desta limitação apontada, justifica-se o uso do Codex a partir de uma visão crítica, em que, para tanto, foram pinçados alguns pontos relevantes do normativo que na visão das autoras se adaptam à realidade dos BA. ${ }^{24}$

A terceira etapa metodológica foi a construção da proposta do Roteiro, que contempla a descrição detalhada de cada item previamente selecionado, conforme disposto no quadro 1.

Para a elaboração desta última etapa, foi realizada adequação a partir do modelo do Roteiro para elaboração do MBP para Indústrias de Alimentos e para Serviços de Alimentação, da Vigilância e Fiscalização Sanitária do Município do Rio de Janeiro. ${ }^{9}$ 


\section{Resultados}

A partir da análise do Check List do Programa Mesa Brasil do Sesc PR, foram elencados dez itens que contemplam a proposta do MBP para BA. Objetivando melhor disposição das informações no Manual, alguns desses itens foram subdivididos e relacionados com as legislações abordadas neste estudo, conforme apresentados no quadro 1.

Quadro 1. Itens selecionados para a proposta de Roteiro para Manual de Boas Práticas para Bancos de Alimentos (BA): visão ampliada, e sua relação com as legislações. Curitiba-PR, 2016.

\begin{tabular}{|l|l|l|}
\hline $\begin{array}{l}\text { ITEM PARA A } \\
\text { PROPOSTA }\end{array}$ & SUBITEM & RELAÇÃO COM A LEGISLAÇÃO \\
\hline & & $\begin{array}{l}\text { Portaria 1.428, PIQs para serviços na área } \\
\text { de alimentos, item VI, letras a (Designação), } \\
\text { b (Classificação), c (Descrição) e d } \\
\text { (Caracterização) }\end{array}$ \\
$\begin{array}{l}\text { 1. IDENTIFICAÇÃO } \\
\text { DO BANCO DE } \\
\text { ALIMENTO (BA) }\end{array}$ & $\begin{array}{l}\text { Tópico não } \\
\text { subdividido }\end{array}$ & $\begin{array}{l}\text { RDC 275, anexo II, letra a, itens 1 (razão } \\
\text { social), 2 (nome fantasia), 3 (alvará e licença } \\
\text { sanitária), } 4 \text { (I.E./ Municipal), 5 (CNPJ), } \\
6 \text { (fone), } 8 \text { (e-mail), 9, 10, 11, 12, 13, 14 } \\
\text { (endereço), 15 (CEP), 21, 22 (R.T.), 23 (R.L.), } \\
16 \text { (ramo de atividade) e 20 (categoria de } \\
\text { produtos) }\end{array}$ \\
\hline $\begin{array}{l}\text { 2. PROGRAMA DE } \\
\text { ATENDIMENTO AO } \\
\text { CONSUMIDOR }\end{array}$ & Tópico não \\
\hline
\end{tabular}

continua 


\begin{tabular}{|c|c|c|}
\hline $\begin{array}{l}\text { ITEM PARA A } \\
\text { PROPOSTA }\end{array}$ & SUBITEM & RELAÇÃO COM A LEGISLAÇÃO \\
\hline \multirow[t]{3}{*}{ 3. INVENTÁRIO } & 3.1. Espaço Físico & $\begin{array}{l}\text { RDC 275, Anexo II, letra B, itens 1.1, 1.2, 1.3 } \\
\text { (edificações e instalações), 1.4 (piso), 1.5 (teto), } \\
1.7 \text { (portas), } 1.8 \text { (janelas e outras aberturas) } \\
1.10 \text { (instalações sanitárias e vestiários), 1.13.1, } \\
1.13 .2 \text { (iluminação), 1.13.3 (instalações elétricas), } \\
\text { 1.14.1, 1.14.2 (ventilação), 1.14.3, 1.14.4 (limpeza } \\
\text { do sistema de climatização), 1.20 (leiaute), } 4.5 .2 \\
\text { (veículo com cobertura para proteção da carga) } \\
\text { RDC 216, ANEXO, itens 4.1.1 (edificação e } \\
\text { instalações), } 4.1 .2 \text { (leiaute), } 4.1 .3 \text { (teto, paredes } \\
\text { e piso), 4.1.4 (portas e janelas), } 4.1 .5 \text { (rede } \\
\text { de esgoto e abastecimento de água), } 4.1 .9 \\
\text { (ventilação e instalações elétricas), 4.1.10 (filtros } \\
\text { para climatização), 4.1.12 e 4.1.13 (instalações } \\
\text { sanitárias e vestiários) }\end{array}$ \\
\hline & $\begin{array}{l}\text { 3.2. Equipamentos, } \\
\text { Móveis e Utensílios }\end{array}$ & $\begin{array}{l}\text { Codex, Seção IV, itens } 4.1 .2 \text { (equipamentos) e } \\
4.3 .2 \text { (equipamentos) }\end{array}$ \\
\hline & $\begin{array}{l}\text { 3.3. Materiais } \\
\text { Descartáveis de } \\
\text { Consumo para } \\
\text { Utilização na Logística }\end{array}$ & Codex, Seção V, item 5.4 (embalagens) \\
\hline
\end{tabular}

continua 


\begin{tabular}{|c|c|c|}
\hline $\begin{array}{l}\text { ITEM PARA A } \\
\text { PROPOSTA }\end{array}$ & SUBITEM & RELAÇÃO COM A LEGISLAÇÃO \\
\hline \multirow{3}{*}{$\begin{array}{l}\text { 4. BOAS PRÁTICAS } \\
\text { PARA A UNIDADE } \\
\text { DE TRANSPORTE }\end{array}$} & $\begin{array}{l}\text { 4.1. Manutenção } \\
\text { Preventiva dos } \\
\text { Veículos e de suas } \\
\text { Câmaras Frias }\end{array}$ & \multirow[t]{2}{*}{$\begin{array}{l}\text { RDC 216, ANEXO, item } 4.1 .16 \text { (manutenção } \\
\text { programada e periódica) } \\
\text { Codex, Seção VIII, item } 8.3 \text { (manutenção e } \\
\text { conservação para transporte de alimentos) }\end{array}$} \\
\hline & 4.2. Controle de Pneus & \\
\hline & 4.3. Higienização & $\begin{array}{l}\text { RDC } 275 \text {, Anexo II, letra B, item 4.5.2 (veículo } \\
\text { limpo) } \\
\text { RDC 216, ANEXO, item 4.2.1, 4.2.3, 4.2.5, } \\
\text { 4.2.7 (higienização) }\end{array}$ \\
\hline \multirow{4}{*}{$\begin{array}{l}\text { 5. BOAS } \\
\text { PRÁTICAS PARA } \\
\text { EQUIPAMENTOS, } \\
\text { UTENSÍLIOS E } \\
\text { ACESSÓRIOS }\end{array}$} & $\begin{array}{l}\text { 5.1. Equipamentos } \\
\text { de Movimentação de } \\
\text { Carga }\end{array}$ & $\begin{array}{l}\text { RDC } 275 \text {, Anexo II, letra } \mathrm{B} \text {, item } 4.5 .3 \\
\text { (transporte mantém a integridade do produto) }\end{array}$ \\
\hline & $\begin{array}{l}\text { 5.2. Dispositivos } \\
\text { Facilitadores de } \\
\text { Segurança para Carga }\end{array}$ & RDC 275, Anexo II, letra B, item 3.5 (EPIs) \\
\hline & $\begin{array}{l}\text { 5.3. Acessórios para } \\
\text { Arranjo e Fixação de } \\
\text { Carga }\end{array}$ & $\begin{array}{l}\text { RDC } 275 \text {, Anexo II, letra } \mathrm{B} \text {, item } 4.5 .3 \\
\text { (transporte mantém a integridade do produto) }\end{array}$ \\
\hline & $\begin{array}{l}\text { 5.4. Acessórios para } \\
\text { Separação da Carga }\end{array}$ & $\begin{array}{l}\text { RDC } 275 \text {, Anexo II, letra B, itens } 4.5 .3 \\
\text { (transporte mantém a integridade do produto) } \\
\text { e } 4.5 .4 \text { (veículo não transporta outras cargas } \\
\text { que comprometam a segurança dos produtos) }\end{array}$ \\
\hline
\end{tabular}




\begin{tabular}{|c|c|c|}
\hline $\begin{array}{l}\text { ITEM PARA A } \\
\text { PROPOSTA }\end{array}$ & SUBITEM & RELAÇÃO COM A LEGISLAÇÃO \\
\hline \multirow{6}{*}{$\begin{array}{l}\text { 6. BOAS PRÁTICAS } \\
\text { PARA O ALIMENTO }\end{array}$} & $\begin{array}{l}\text { 6.1. Pré-preparação da } \\
\text { Carga e Identificação } \\
\text { para Rastreabilidade } \\
\text { dos Produtos }\end{array}$ & $\begin{array}{l}\text { RDC } 275 \text {, Anexo II, letra B, itens } 4.3 .1 \text { e } 4.3 .2 \\
\text { (etiqueta de identificação e acondicionamento } \\
\text { na embalagem) }\end{array}$ \\
\hline & $\begin{array}{l}\text { 6.2. Inspeção de } \\
\text { Embarque }\end{array}$ & $\begin{array}{l}\text { Codex, Seção IV, item } 4.4 .5 \text { (controle de } \\
\text { temperatura). Seção VIII, item } 8.2 \text { (manutenção } \\
\text { da temperatura para proteger o alimento) }\end{array}$ \\
\hline & $\begin{array}{l}\text { 6.3. Paletização e } \\
\text { Unitização }\end{array}$ & $\begin{array}{l}\text { RDC } 275 \text {, Anexo II, letra B, item } 4.5 .3 \\
\text { (transporte mantém a integridade do produto) }\end{array}$ \\
\hline & $\begin{array}{l}\text { 6.4. Arrumação da } \\
\text { Carga }\end{array}$ & $\begin{array}{l}\text { RDC } 275 \text {, Anexo II, letra B, item } 4.5 .3 \\
\text { (transporte mantém a integridade do produto) }\end{array}$ \\
\hline & $\begin{array}{l}\text { 6.5. Inspeção de } \\
\text { Desembarque }\end{array}$ & $\begin{array}{l}\text { RDC 275, Anexo II, letra B, item 4.1.1 } \\
\text { (recepção em área protegida), 4.1.2 e 4.1.5 } \\
\text { (inspeção e seleção dos produtos), 4.1.8, 4.1.9, } \\
\text { 4.1.10, 4.3.2, 4.3.3 e 4.3.5 (armazenamento) } \\
\text { RDC 216, ANEXO, itens 4.7.2 (recepção em } \\
\text { área protegida), 4.7.3 (inspeção dos produtos), } \\
\text { 4.7.5 e 4.7.6 (armazenamento adequado) }\end{array}$ \\
\hline & $\begin{array}{l}\text { 6.6. Reprovação e } \\
\text { Devolução da Carga }\end{array}$ & $\begin{array}{l}\text { RDC } 275 \text {, Anexo II, letra B, item } 4.1 .5 \text { e } 4.3 .8 \\
\text { (reprovação e devolução da carga) } \\
\text { RDC 216, ANEXO, item 4.7.4 (produtos } \\
\text { reprovados) }\end{array}$ \\
\hline \multirow{3}{*}{$\begin{array}{l}\text { 7. BOAS PRÁTICAS } \\
\text { PARA O MANUSEIO } \\
\text { DE ALIMENTOS }\end{array}$} & $\begin{array}{l}\text { 7.1. Procedimento de } \\
\text { Carga e Descarga }\end{array}$ & \multirow{3}{*}{$\begin{array}{l}\text { RDC } 275 \text {, Anexo II, letra B, itens } 4.1 .11 \text { (rede } \\
\text { de frio adequada), } 4.5 .1 \text { e } 4.5 .5 \text { (temperatura } \\
\text { adequada para transporte) }\end{array}$} \\
\hline & $\begin{array}{l}\text { 7.2. Acompanhamento } \\
\text { Durante o } \\
\text { Deslocamento }\end{array}$ & \\
\hline & $\begin{array}{l}\text { 7.3. Fracionamento de } \\
\text { Alimentos }\end{array}$ & \\
\hline
\end{tabular}




\begin{tabular}{|c|c|c|}
\hline $\begin{array}{l}\text { ITEM PARA A } \\
\text { PROPOSTA }\end{array}$ & SUBITEM & RELAÇÃO COM A LEGISLAÇÃO \\
\hline $\begin{array}{l}\text { 8. BOAS } \\
\text { PRÁTICAS PARA } \\
\text { ABASTECIMENTO } \\
\text { DE ÁGUA }\end{array}$ & $\begin{array}{l}\text { Tópico não } \\
\text { subdividido em } \\
\text { subitem }\end{array}$ & $\begin{array}{l}\text { RDC 275, Anexo II, letra B, itens 1.17.3, 1.17.4, } \\
\text { 1.17.5, 1.17.6 e 1.17.7 (reservatório de água) } \\
\text { RDC 216, ANEXO, item 4.4.4 (descrição e } \\
\text { higienização do reservatório de água) }\end{array}$ \\
\hline \multirow{3}{*}{$\begin{array}{l}\text { 9. BOAS PRÁTICAS } \\
\text { PARA OPERADORES } \\
\text { DE TRANSPORTE }\end{array}$} & $\begin{array}{l}\text { 9.1. Recursos } \\
\text { Humanos }\end{array}$ & $\begin{array}{l}\text { RDC } 275 \text {, Anexo II, letra A, itens } 18 \text { e } 19 \\
\text { (número de funcionários e turnos) }\end{array}$ \\
\hline & $\begin{array}{l}\text { 9.2. Uso de } \\
\text { Uniformes, } \\
\text { Equipamentos de } \\
\text { Proteção Individual } \\
\text { (EPI) e Identificação } \\
\text { (Crachá) }\end{array}$ & $\begin{array}{l}\text { RDC } 275 \text {, Anexo II, letra B, itens 3.1.1, 3.1.2 } \\
\text { (uniforme adequado), } 3.5 \text { (EPIs) }\end{array}$ \\
\hline & $\begin{array}{l}\text { 9.3. Regras para } \\
\text { visitantes }\end{array}$ & RDC 216, ANEXO, item 4.6 .8 (visitantes) \\
\hline \multirow{4}{*}{$\begin{array}{l}10 . \\
\text { DOCUMENTAÇÃO E } \\
\text { REGISTRO DO BA }\end{array}$} & $\begin{array}{l}\text { 10.1. Documentação } \\
\text { do Doador e do } \\
\text { Receptor dos Produtos } \\
\text { 10.2. Documentação } \\
\text { da Unidade de } \\
\text { Transporte }\end{array}$ & \multirow{4}{*}{$\begin{array}{l}\text { Codex, Seção V, item } 5.7 \text { (documentação e } \\
\text { registro) }\end{array}$} \\
\hline & $\begin{array}{l}\text { 10.3. Documentação } \\
\text { do Produto } \\
\text { Transportado }\end{array}$ & \\
\hline & $\begin{array}{l}\text { 10.4. Documentação } \\
\text { do Operador de } \\
\text { Transporte }\end{array}$ & \\
\hline & $\begin{array}{l}\text { 10.5. Registros e } \\
\text { Controles }\end{array}$ & \\
\hline
\end{tabular}




\section{Proposta de Roteiro para o MBP para BA: das normativas à aplicabilidade}

Após relacionar os itens e subitens aos marcos normativos, considerando que o BA possui atividades peculiares ao serviço, que podem causar dificuldade de compreensão, identificou-se a necessidade de detalhar as informações a ser apresentadas em cada tópico do Manual.

É necessário esclarecer a priori que a proposta procurou aventar inúmeras possibilidades ocorridas em BA, entretanto, ressalta-se a necessidade de adequação do Roteiro a cada realidade, pautando-se sempre em um olhar ampliado com uma relativa flexibilidade de acordo com a estrutura física, as possibilidades financeiras, o porte do BA (pequeno, médio, grande), o tipo de produto manipulado, o grau de manipulação, o tempo de armazenamento, o quadro de recursos humanos (contratados/voluntários), os equipamentos disponíveis, o clima da região, o tipo de distribuição das doações, a classificação de risco do estabelecimento, as normas sanitárias regionais e municipais, entre outros fatores que possam ser relevantes.

A proposta do Roteiro para Elaboração do MBP para BA: visão ampliada é composta pelos itens: 1. Identificação do BA, 2. Programa de Atendimento ao Consumidor, 3. Inventário, 4. Boas Práticas para a Unidade de Transporte, 5. Boas Práticas para Equipamentos, Utensílios e Acessórios, 6. Boas Práticas para o Alimento, 7. Boas Práticas para o Manuseio de Alimentos, 8. Boas Práticas para Abastecimento de Água, 9. Boas Práticas para Operadores de Transporte, 10. Documentação e Registro do BA.

No primeiro tópico do Manual, intitulado Identificação do $B A$, a proposta contempla a descrição da razão social, o nome fantasia, o CNPJ, a Inscrição Estadual/Municipal, o e-mail, endereço, horário de funcionamento, telefone, responsável técnico, se possuir, identificação e comprovação da capacitação do responsável técnico, se aplicável, responsável legal, certificado de inspeção sanitária e alvará de funcionamento. ${ }^{20,22}$

Propõe-se ainda que na Identificação seja elaborada a caracterização do estabelecimento, ou seja, se o mesmo é público ou privado, se trabalha na modalidade BA, Colheita Urbana ou misto. ${ }^{c}$ Quais os tipos de produtos coletados, por exemplo, hortaliças e frutas, produtos industrializados, congelados, refrigerados, de higiene e limpeza, utensílios, roupas, ou outras doações em geral. Os tipos de doadores, por exemplo, indústrias de alimentos, atacadistas, mercados, panificadoras, mercearias, frutarias, produtores rurais, cooperativas agrícolas. Os tipos de instituições e/ou entidades beneficiárias, por exemplo, se creches filantrópicas, associações de pais e mestres, instituições de longa permanência para idosos, famílias em situação de vulnerabilidade social,

c Na modalidade de Colheita Urbana, os alimentos são coletados nos doadores e entregues diretamente às entidades beneficiárias, sem formação de estoque. Na modalidade BA, as doações são coletas no doador e/ ou recebidas pelo doador e as entidades realizam a retirada dos produtos no BA. ${ }^{25}$ 
comunidades indígenas, comunidades quilombolas, assentados da reforma agrária, entre outros. A recomendação de que se faça este descritivo deve-se à necessidade de conhecer o público ao qual se prevê o atendimento. Esta informação qualifica o BA e sua premissa, que é de atender as pessoas em situação de vulnerabilidade social e alimentar.

A respeito do segundo item da proposta do Manual, denominado Programa de Atendimento ao Consumidor, sugere-se que seja descrita a forma de atendimento e/ou comunicação, tanto no caso das organizações e/ou instituições doadoras, como das entidades receptoras, como, por exemplo, se é disponibilizado o endereço, o e-mail, o telefone do Banco, se são realizadas visitas para conhecimento/reconhecimento e/ou acompanhamento (entre as instituições que doam e as que recebem), entre outras informações necessárias. ${ }^{20}$ Ao descrever este mecanismo de comunicação e/ou contato, vão se ampliar as possibilidades de estreitamento dos laços entre os agentes e, principalmente, entre a equipe que gere o processo.

O terceiro tópico da proposta é o Inventário. Como o item demanda descrições distintas, recomenda-se que o mesmo seja subdividido em três tópicos, que são: 3.1. Espaço Físico, 3.2. Equipamentos, Móveis e Utensílios e 3.3. Materiais Descartáveis de Consumo para Utilização na Logística.

No que se refere ao subitem Espaço Físico, sugere-se que sejam detalhadas todas as áreas do $\mathrm{BA}$, iniciando pelos arredores, que podem conter informações sobre áreas circunvizinhas (outras entidades que possam ser identificadas como parceiras), vias de acesso interno, se são pavimentadas, se possuem escoamento adequado, condições de salubridade, se estão livres de vetores e animais, de acúmulo de lixo ou água estagnada, condições urbanas, se é área urbana, rural, mista ou de comunidade. Esta descrição potencializa também reconhecer alguns fatores limites no âmbito da logística e, assim, garantir alternativas que possam ser utilizadas e/ou acionadas em nível local.

É recomendado ainda que espaços como Garagem, espaço para higienização de utensílios, espaço para higienização de veículos, estoque de materiais descartáveis, de higiene e limpeza, arquivo de documentos, escritório, entre outros espaços que possam existir no BA, também sejam descritos e especificados no subitem Espaço Físico. ${ }^{21,22}$ É possível, a partir destas descrições adicionais, que o BA incremente outras etapas no fluxo de recebimento e escoamento, ou, ainda, viabilize outros projetos que possam valorizar a existência do BA naquela comunidade.

Sugere-se que no tópico 3.1 sejam descritas também informações sobre os Vestiários e sanitários, enfatizando como ocorre a separação entre a área de armazenamento de alimentos e os vestiários e sanitários, se estão identificados e são de uso exclusivo para manipuladores de alimentos, se são independentes para cada sexo, se as portas externas são dotadas de fechamento automático, 
como molas ou outros, se possuem lavatório para as mãos com todas as facilidades, ${ }^{\mathrm{d}}$ se existem coletores e se são de acionamento sem contato manual, se possuem ducha ou chuveiro, armários individuais, entre outros. ${ }^{21,22}$

Neste subitem propõe-se descrever também sobre os Armazéns para estoque de produtos secos, não perecíveis ou semiperecíveis e câmaras frias. ${ }^{21,22}$

A descrição de cada espaço físico citado anteriormente deve conter informações sobre o leiaute, como, por exemplo, as dimensões dos espaços e localizações, se apresentam medidas de proteção contra contaminação cruzada. Informações sobre teto, forro e cobertura dos espaços, em relação ao material que são constituídos, se são impermeáveis e de cor clara. ${ }^{21,22}$ As descrições solicitadas neste item servem para garantir ao BA sua capacidade de manipular, de forma segura, os alimentos. Também se sugere detalhar informações sobre as Paredes das áreas, descrevendo o material com que são construídas, bem como tipos e cores de pinturas e revestimentos. ${ }^{22}$ Em relação aos Pisos das áreas, detalhar o material de que são constituídos, quais os tipos, se são antiderrapantes, impermeáveis e se possuem escoamento adequado. ${ }^{22}$ Em seguida, especificar as Aberturas dos espaços, como, por exemplo, docas, portas, portões e janelas, onde se deve descrever o tipo de janela, porta, doca e portões, o material com que são construídos, tipo de vidro, madeira, alumínio, inox, ferro, entre outros, tipos e cores de pinturas, se possuem grades ou telas removíveis, se são ajustados aos batentes e se as portas externas são dotadas de fechamento automático. ${ }^{21,22}$ Levando em consideração que a manipulação de alimentos exige certas habilidades, nesse caso, ao seguir as normativas vigentes, uma série de requisitos são necessários para a sua descrição. Contudo, ao se conhecer a realidade do equipamento (BA), confere à equipe gestora melhor apropriação técnica para reivindicar melhores condições de funcionamento e/ou formular planos de ação para implantação a curto, médio e longo prazo, de acordo com as características de cada local.

Outras informações descritivas também possibilitam conhecer e reconhecer limites e potencialidades do equipamento. Inserir informações sobre a Iluminação das áreas, se é natural ou artificial, como é constituída, inclusive o número de luminárias, número de lâmpadas, tipo de lâmpadas, se possui proteção contra queda e explosão, no caso de não ser lâmpada de LED, se possui ofuscamento, sombras ou cantos escuros. ${ }^{21,22}$ Informar se a Ventilação dos espaços é natural ou mecânica e qual o tipo, se o fluxo de ar não incide diretamente sobre os alimentos. ${ }^{21,22}$ Acrescentar dados sobre a Rede elétrica, quem é o fornecedor de energia, qual o tipo de fiação, se está embutida ou protegida em tubulações, se permite a higienização dos ambientes, qual a localização do(s) quadro(s) de energia, se o(s) mesmo(s) está(ão) identificado(s)..$^{21,22}$

d Entende-se as facilidades para higienização das mãos como: água corrente, sabonete inodoro antisséptico, ou sabonete inodoro e produto antisséptico, papel toalha não reciclado, procedimento sobre higienização de mãos afixado em local visível, coletor de resíduos com acionamento não manual. 
Tratando-se de Segurança Alimentar e Nutricional (SAN), outras dimensões precisam ser incorporadas, não apenas por se considerar a perspectiva do alimento seguro, mas por compreender que o contexto social e político (e do acesso às políticas públicas que viabilizam o alcance a bens e serviços) está intrinsicamente relacionado, sendo, portanto, fundamental. Desse modo, explicitar como é constituída a Rede de esgoto, qual o tipo da rede, se é interligada à rede pública, se existe fossa séptica, se existe caixa de gordura, se os ralos são sifonados. ${ }^{22} \mathrm{Ou}$, ainda, quanto ao abastecimento de água, explicar o tipo de rede, se possui caixa d'água, se possui poço, se a água vem direto da rua, se possui torneira com água quente, entre outros. ${ }^{22}$

Em relação aos Equipamentos de filtros para climatização, se aplicável, explicar como é realizada a limpeza e manutenção dos filtros, qual a frequência e como é feito o registro, se o registro está afixado em local visível. ${ }^{21,22}$ Aqui, predomina-se a compreensão da SAN sob a perspectiva do alimento seguro, portanto, princípio básico dos BA.

Propõe-se que sejam relatados também quando aplicável, os dados sobre a frota, listando o número de veículos, tipo de veículos e opcionais. ${ }^{e}$ Acrescentar ainda a marca, modelo, placa, ano de fabricação, no da licença sanitária do(s) veículo(s), capacidade máxima de carga, cubagem, medidas internas do baú e altura total do(s) mesmo(s). Detalhar se possui separação entre a cabine e o furgão, bem como facilidades para higienização das mãos nos veículos, como, por exemplo, sabonete líquido neutro, papel-toalha e álcool gel a 70\% e, quando possível, reservatório de água.

Se o(s) veículo(s) possuir(em) furgão, descrever também o tipo, se é de carroceria aberta ou fechada, seca ou refrigerada, se possui isolamento, iluminação, portas, cortinas nas portas para manutenção de temperatura, estrados, termômetro, registro para vedação dos drenos, entre outros. Caso o furgão seja refrigerado/congelado, detalhar dados referentes ao motor, como, por exemplo, o modelo, fornecedor, data da instalação, temperatura máxima e mínima, formas de acionamento, se via motor ou energia elétrica, tipo de tomada e voltagem para conectar na energia elétrica. Se o baú possuir isolamento térmico, listar o tipo de material de que é constituído. Declarar ainda se o veículo possui identificação nas portas sobre o transporte de alimentos perecíveis. ${ }^{21}$

O segundo subitem da seção de Inventário refere-se aos Equipamentos, Móveis e Utensílios, nesta etapa deve-se listar dados sobre a descrição, a quantidade e o local de armazenamento dos equipamentos, móveis e utensílios que o BA possui. ${ }^{24}$

Para finalizar o tópico do Inventário, são especificados os Materiais Descartáveis de Consumo para Utilização na Logística, e nesse sentido sugere-se listar todos os materiais comumente utilizados para esta atividade, incluindo suas descrições, o consumo médio mensal e seus locais de armazenamento no armazém e nos veículos. ${ }^{24}$ São exemplos de materiais descartáveis de consumo

e Como, por exemplo, direção hidráulica, vidro elétrico, faixa refletora, aviso sonoro de ré, luz de ré, ar condicionado, ar quente, calhas nas janelas, entre outros. 
para utilização na logística, os sacos plásticos para coleta, sacos plásticos para fracionamento, lacres para sacos plásticos, luvas descartáveis para coleta, entre outros. Considerando a compreensão de SAN, que prevê aspectos relacionados à sustentabilidade, ao descrever este item, o equipamento (BA) poderá inovar ao trazer elementos que vislumbrem a substituição dos itens descartáveis por itens com características mais duradouras (sacolas retornáveis de tecido, lacres reutilizáveis, luvas reutilizáveis de PVC, recipientes de armazenamento em condições de higiene, entre outros).

O tópico quatro da proposta para elaboração do MBP para BA é referente às Boas Práticas para a Unidade de Transporte, e a proposta é que este também seja subdividido em três subitens, contemplando: 4.1. Manutenção Preventiva dos Veículos e de suas Câmaras Frias, 4.2. Controle de Pneus e 4.3. Higienização dos mesmos. Em relação à Manutenção Preventiva dos Veículos e de suas Câmaras Frias, bem como ao Controle de Pneus, deve-se verificar a indicação dos fabricantes sobre os itens a ser monitorados permanentemente para manutenção preventiva dos veículos, de suas câmaras frias (isolamento e equipamento de refrigeração) e dos pneus, para descrevê-los no Manual. Listar também a forma de controle desses itens, e com referência aos pneus, propõe-se ainda que sejam acrescentados os modelos e a vida útil dos pneus que estão atualmente instalados no(s) veículo(s). ${ }^{22,24}$ Já no subitem que trata da Higienização e limpeza, sugere-se que seja descrita a frequência, o procedimento, o responsável e a forma de registro da higienização dos veículos. ${ }^{21,22}$

O próximo tópico da proposta do Manual refere-se às Boas Práticas para Equipamentos, Utensílios e Acessórios, e orienta-se que seja separado em quatro subitens, sendo: 5.1. Equipamentos de Movimentação de Carga, 5.2. Dispositivos Facilitadores de Segurança para Carga, 5.3. Acessórios para Arranjo e Fixação de Carga e 5.4. Acessórios para Separação da Carga. No que se refere aos Equipamentos de Movimentação de Carga, a sugestão é que sejam especificados os equipamentos de movimentação de carga utilizados pelo Banco e suas quantidades, como, por exemplo, carrinhos para carga, paleteiras, empilhadeiras, entre outros. ${ }^{21}$

O subitem que trata dos Dispositivos Facilitadores de Segurança para Carga contempla a descrição dos equipamentos de proteção individual e coletiva usados pelos funcionários no processo de carga e descarga, como, por exemplo, sapatos de segurança, luvas para carga, jaquetas térmicas e gorro, que são empregados quando se faz necessário acessar câmaras refrigeradas ou congeladas, entre outros. ${ }^{21} \mathrm{O}$ olhar ampliado da qualidade também considera os aspectos que tratam da segurança e ergonomia do trabalhador e da trabalhadora.

No que diz respeito aos Acessórios para Arranjo e Fixação de Carga, deve-se descrever aqueles disponíveis para fixação da carga que possuem como função evitar que ela se movimente durante o transporte e cause danos aos produtos, e, ainda, por questões de segurança no transporte. São exemplos de dispositivos para fixação de carga: cordas, encerados, trava-paletes, entre outros. Pode ser acrescentada também a descrição de como ocorre a aplicação dos dispositivos em cada caso e quais as medidas preventivas para que os mesmos não contaminem os alimentos. ${ }^{21}$ 
Quanto aos Acessórios para Separação da Carga, deve-se descrever os acessórios disponíveis para esta atividade (divisórias, repartidores e outros). Esses acessórios possuem a função de evitar a contaminação dos alimentos e/ou manter sua conservação, no caso de o mesmo veículo necessitar carregar outros produtos, além de alimentos na mesma viagem, ou no caso de precisar carregar alimentos refrigerados e alimentos em temperatura ambiente, concomitantemente. ${ }^{21}$

O sexto tópico que trata a proposta do MBP é denominado Boas Práticas para o Alimento, e a sugestão é para que seja desmembrado em seis subitens, a saber: 6.1. Pré-preparação da Carga e Identificação para Rastreabilidade dos Produtos, 6.2. Inspeção de Embarque, 6.3. Paletização e Unitização, ${ }^{\text {6 }}$ 6.4. Arrumação da Carga, 6.5. Inspeção de Desembarque, 6.6. Reprovação e Devolução da Carga.

O objetivo da Pré-preparação da Carga e Identificação para Rastreabilidade dos Produtos é apresentar onde (recipiente) e como são acondicionados os produtos coletados, se são identificados com data, nome do doador, tipo de produto, quantidade e validade (tempo de consumo), ou demais informações para que seja viabilizada a rastreabilidade do mesmo. ${ }^{21}$ Esta descrição é primordial para estabelecer um real comprometimento entre quem doa e quem recebe os alimentos. Desse modo, ao fazer tais registros ficam impressas - por parte de quem doa - as intenções de seguir um protocolo que estabelece laços de solidariedade, mas com responsabilidade e seriedade. Já por parte de quem recebe, simbolicamente, interpreta-se relações de cuidados para quem consumirá tais produtos.

A Inspeção de embarque contempla informações sobre o preparo das condições da câmara do veículo para armazenar os produtos que serão transportados, como, por exemplo, se é necessário ligar a câmara fria com antecedência e qual a temperatura ideal para cada tipo de produto. Aconselha-se que seja descrito também, no caso de alimentos refrigerados, como é realizada a aferição da temperatura do alimento e da câmara do veículo. ${ }^{24}$ Já para o subitem que trata da Paletização e Unitização, a intenção é detalhar esses procedimentos, no caso dos Bancos que os utilizam para arrumação da carga. ${ }^{21}$

No subitem 6.4. (arrumação da carga), recomenda-se o esmiuçamento da forma de arrumação da carga, listando distâncias mínimas do piso e das paredes dos veículos, recipientes em que os mesmos são acondicionados e organizados, amarração da carga, disposição e ordem dos produtos, sendo os mais perecíveis mais próximos ao motor da câmara e os menos perecíveis, mais distantes, entre outros. ${ }^{21}$ No que tange à Inspeção de Desembarque, a proposta é que seja descrito no Manual os critérios observados pelo funcionário responsável pela conferência da carga quando a mesma é descarregada dos veículos para o armazém do BA. Também deve estar exposto o procedimento para organização dos produtos no armazém, e nesse caso, pode ser apresentado o empilhamento

f Unitização é reunir cargas de diversas naturezas num só volume, para fins de transporte, através de amarrados, tambores, caixas, redes, paletes, containers, entre outros. 
de caixas, os locais para armazenar produtos perecíveis (se há controle e registro de temperaturas), semiperecíveis e não perecíveis, a distância do piso e das paredes, a necessidade de estrados, paletes ou outros, para ficar sob os produtos, a disposição dos produtos seguindo as datas de validade e o estado de conservação, entre demais informações importantes ao serviço. ${ }^{21,22}$

Também pode ser registrado se o desembarque dos produtos é realizado em local protegido, ou seja, se existe uma cobertura (telha, toldo, acrílico, outros), onde o caminhão possa ser colocado sob a mesma para descarregar os produtos, sem o risco de contaminação, que pode ocorrer, por exemplo, em dias de chuva, caso não possua cobertura. ${ }^{21,22}$ No subitem 6.6. Reprovação e Devolução da Carga, propõe-se que seja detalhado o procedimento para devolução ou o descarte dos alimentos, quando recebidos do doador e classificados como impróprios para o consumo pelos colaboradores do BA, aconselha-se descrever inclusive se são devidamente identificados, caso necessitem de tempo de espera para devolução e/ou descarte. ${ }^{21,22}$

O tópico 7 da proposta dispõe sobre as Boas Práticas para o Manuseio de Alimentos; para tanto, orienta-se que seja subdividido em três campos, objetivando abordar sobre 7.1. Procedimento de Carga e Descarga, 7.2. Acompanhamento Durante o Deslocamento, 7.3. Fracionamento de Alimentos. No item 7.1. Procedimento de Carga e Descarga, aconselha-se que seja descrito o procedimento de carga e descarga dos alimentos, especificando os funcionários responsáveis, os equipamentos utilizados e os cuidados inerentes ao processo.

Sobre o Acompanhamento Durante o Deslocamento, a proposta é que sejam detalhadas informações a respeito da rota estabelecida e os monitoramentos indispensáveis, como é o caso do acompanhamento da temperatura da câmara frigorífica do veículo, descrevendo os cuidados tomados para manutenção da cadeia de frio, no caso de alimentos refrigerados ou congelados, o controle da temperatura da câmara do veículo por meio de termômetros e planilhas, a prevenção de saída de ar frio com cortinas de PVC nas portas, o tempo de permanência das portas abertas e a chegada dos alimentos, sendo descarregados diretamente em câmaras resfriadas já em temperatura ideal. ${ }^{21}$ A finalidade do subitem Fracionamento de Produtos é apresentar informações sobre esse procedimento, visto que alguns BA, ocasionalmente, recebem produtos embalados em grandes quantidades, havendo necessidade de fracionar os alimentos para realizar a distribuição às instituições e famílias beneficiárias. Sugere-se que seja detalhado o local em que é realizada esta atividade, quais os cuidados na manipulação, utensílios e embalagens utilizadas, forma de identificação das embalagens, entre outras informações pertinentes.

O oitavo tópico da proposta do Manual dispõe sobre Boas Práticas para Abastecimento de Água, e nesse sentido, orienta-se para que seja informada a fonte de água de abastecimento do BA, se água vem encanada diretamente da rua, ou se possui reservatório, e se possuir, descrever o material de que é constituída a caixa d'água, qual as condições em que se encontra (livre de vazamentos, deterioração das paredes, descascamento, condições da tampa), qual o tamanho, onde está localizada, qual o 
procedimento e a periodicidade da higienização, se existe registro e se o mesmo está arquivado. Se a higienização for realizada por profissional do próprio estabelecimento, descrever se o mesmo está apto a realizar o procedimento e se existem registro e arquivo do treinamento. Por outro lado, se a higienização for feita por empresa terceirizada, descrever se são solicitados os documentos da empresa (Alvará de funcionamento, Licença Sanitária, nome e número do registro do responsável técnico, procedimento realizado, produtos utilizados, certificado do serviço) e se são arquivados. ${ }^{21,22}$

O tópico referente às Boas Práticas para Operadores de Transporte pode ser abordado a partir de três subitens, que são: 9.1. Recursos Humanos, 9.2. Uso de Uniformes, Equipamentos de Proteção Individual (EPI) e Identificação (Crachá), 9.3. Regras para visitantes. O subitem 9.1. Recursos Humanos visa descrever o procedimento para contratação/recrutamento de colaboradores, estagiários e voluntários, quando aplicável, exames admissionais e periódicos, treinamentos, quadro de funcionários/voluntários, descrições das funções e os horários das jornadas de trabalho. ${ }^{21}$

No subitem referente ao Uso de Uniformes, Equipamentos de Proteção Individual (EPI) e Identificação (Crachá), sugere-se que sejam descritos o tipo de uniforme, EPI e identificação entregues aos funcionários/voluntários, se existem registros das entregas e onde são arquivados. ${ }^{21}$ Quanto às Regras para Visitantes, a proposta é descrever os critérios definidos para visitantes, sobretudo referente ao acesso às áreas de manipulação, como, por exemplo, no momento do fracionamento de alimentos. ${ }^{22}$

O último tópico da proposta é relativo à Documentação e Registros do BA, desmembrado nos subitens 10.1. Documentação do Doador e do Receptor dos Produtos, 10.2. Documentação da Unidade de Transporte, 10.3. Documentação do Produto Transportado, 10.4. Documentação do Operador de Transporte, 10.5. Registros e Controles. Na Documentação do Doador e do Receptor dos Produtos, sugere-se que seja descrita a documentação utilizada para registro de doações recebidas e de doações efetuadas pelo BA, listando os itens preenchidos, como são entregues, onde são arquivados, por quanto tempo são arquivados, entre outras informações importantes. ${ }^{24}$ No subitem que trata sobre Documentação da Unidade de Transporte, descrever a documentação de importância para o veículo e onde encontra-se arquivada, como, por exemplo, licença sanitária do veículo, certificado de vistoria do veículo, licenciamento e cartão do seguro, se aplicável. ${ }^{24}$

Já em relação à Documentação do Produto Transportado, descrever a documentação de importância para o transporte dos produtos, como, por exemplo, recibos de doação, notas fiscais, notas de remessa, entre outros. ${ }^{24}$ Sobre a Documentação do Operador de Transporte, detalhar a documentação de importância para o operador de transporte, que no caso é a Carteira Nacional de Habilitação $(\mathrm{CNH})$ e crachá de identificação. Listar também onde está arquivada a cópia da $\mathrm{CNH}$ na área administrativa. ${ }^{24}$ Descrever ainda os Registros e Controles realizados, como, por exemplo, planilhas de controle de quilometragem, combustível, condutor, manutenções, controles de temperatura (veículo, armazém, alimentos), inspeções, diário de bordo, entre outros. ${ }^{24}$ 
É pertinente destacar que o MBP deve retratar exatamente a realidade do BA, no momento da elaboração do documento. Recomenda-se que o MBP contenha cabeçalho e rodapé. O cabeçalho pode ser formatado com a logo da empresa (se houver), o Título: "Manual de Boas Práticas - Banco de Alimentos (nome do Banco)", o número da revisão, a data da última revisão e a paginação. O rodapé pode conter o nome dos ou das responsáveis pela elaboração e aprovação do Manual. Também é importante escrever no documento qual é a maneira de disponibilização do MPB aos funcionários. ${ }^{24}$ Este aviso assegura à equipe que o seu dever de socializar a informação será cumprido da melhor forma possível.

Por fim, é importante reforçar que a proposta do Manual é baseada em diversas situações - de distintas realidades - que podem ocorrer entre os BA, assim sendo, ocasionalmente, itens selecionados neste trabalho podem não ser aplicáveis na sua totalidade para alguns BA. Por outro lado, podem surgir situações aplicáveis que não foram descritas na proposta, isto acontece principalmente pela dinamicidade desses equipamentos, mas também pela incipiência de trabalhos na literatura, tratando-se deste setor. Sob as diferentes perspectivas, ressalta-se a relevância para um BA em dispor de um Manual orientativo, não apenas para cumprir com requisitos técnicos, mas por garantir a segurança nos procedimentos.

Reitera-se o objetivo do Roteiro de orientar e não de demandar/definir/obrigar os BA a cumprirem os itens reunidos no presente artigo.

Considera-se uma limitação a utilização das normas sanitárias internacionais e federais como recurso metodológico, o que torna o material abrangente e atribui característica não regionalizada, principalmente diante da diversidade brasileira. Outra questão limitadora é que as normas são elaboradas principalmente para a produção de alimentos em larga escala, fato que lhes conferem uma maior necessidade de cumprir com determinadas exigências sanitárias a fim de não gerar riscos à população.

A soma destes fatores pode refletir em dificuldade na aplicabilidade dessas normas para os BA, sobretudo para os filantrópicos, que comumente não possuem mão de obra fixa - em geral, contam com a ajuda de voluntários para a operacionalização dos processos -- e os espaços físicos são "cedidos" por organizações e/ou entidades que, na maioria das vezes, tendem a ver o tema (da SAN) como sendo uma estratégia passível de investimento.

Diante do exposto, é necessário destacar que o MBP para BA deve ser elaborado abordando os itens que se adaptem ao estabelecimento, descrevendo-os de forma mais detalhada ou mais sucinta e, obviamente, trazendo o componente da particularidade que lhe é peculiar.

Importante reforçar também que as legislações exigem padrões de estrutura, equipamentos e instalações que muitas vezes são inatingíveis. As características de alguns BA exigem, de certa forma, outra proposta de MBF que considere, sobretudo, um olhar ampliado sob a perspectiva 
da SAN, mas sem negligenciar os aspectos sanitários. Por exemplo, a prática cotidiana de seguir com determinadas orientações higiênicas assume igual relevância, sendo possível ter o processo como condição à qualidade sanitária dos produtos. ${ }^{26}$

\section{Conclusão}

A proposta do Roteiro para Elaboração do Manual, específico para os BA, possibilita a abordagem de controles de qualidade peculiares ao serviço, inclui itens que normalmente não são contemplados em Manuais de Boas Práticas de serviços de alimentação, como, por exemplo, a seleção dos produtos nos fornecedores, os processos logísticos, a documentação pertinente para receber e efetuar as doações, entre outros. Dessa forma, o roteiro contempla a demanda de elaboração de materiais específicos para o setor, no entanto, percebe-se a necessidade de novos trabalhos que pautem as realidades dos BA, visando aprofundar a temática, instrumentalizar profissionais que atuam na área, bem como promover a SAN dos chamados centros consumidores (ou entidades recebedoras).

Por fim, é importante destacar que o Roteiro apenas norteia, dá elementos para a implantação e a manutenção das Boas Práticas nos BA. Em contrapartida, ressalta-se que o documento por si só não promove a SAN dos beneficiários receptores, pois existe a necessidade de executar sistematicamente o que está descrito e/ou realizar adaptações para garantir o controle de qualidade dos alimentos manipulados pelo BA. Nesse sentido, aponta-se para a sensibilização dos Gestores dos Bancos, a fim de canalizar esforços e disponibilizar recursos financeiros, estrutura física adequada e mão de obra qualificada para que a qualidade dos alimentos doados possa ser garantida continuamente. De outro modo, potencializar as equipes que trabalham com os equipamentos, tais quais os BA, com uma perspectiva ampliada no quesito da qualidade dos alimentos é primordial para garantir que apenas a dimensão da SAN - que diz respeito ao alimento seguro - seja cumprida conforme sua realidade e que as relações sociais imbuídas nesse processo de doar-e-receber sejam asseguradas.

\section{Colaboradores}

Paula NF trabalhou na concepção do artigo, consultas bibliográficas e elaboração do texto; Assis L trabalhou na concepção do artigo, orientação da elaboração do texto, revisão e análise final do artigo; Ribeiro CSG e Bezerra I atuaram com contribuições ao texto, revisão e análise final do artigo.

Conflito de Interesses: Os autores declaram não haver conflito de interesses. 


\section{Referências}

1. Brasil. Presidência da República. Lei no 11.346, de 15 de setembro de 2006. Cria o Sistema Nacional de Segurança Alimentar e Nutricional - SISAN com vistas a assegurar o direito humano à alimentação adequada, institui a Política Nacional de Segurança Alimentar e Nutricional - PNSAN, estabelece os parâmetros para a elaboração do Plano Nacional de Segurança Alimentar e Nutricional, e dá outras providências. Diário Oficial da União 18 set. 2006.

2. Prezotto LL. Qualidade ampla: referência para a pequena agroindústria rural inserida numa proposta de desenvolvimento regional descentralizado. Anais do 3o Colóquio Internacional sobre Transformações Territoriais; 23-25 ago. 2000; Florianópolis; UFSC.

3. São José JFB, Coelho AIM, Ferreira KR. Avaliação das boas práticas em unidade de alimentação e nutrição no município de Contagem-MG. Alim Nutr. 2011; 22(3):479-487.

4. Food Quality and Safety Systems. A training manual on food hygiene and the Hazard Analysis and Critical Control Point (HACCP) System. Rome: FAO; 1998. Disponível em: http://www.fao.org/ docrep/w8088e/w8088e00.htm\#Contents

5. Lucchese G. Descentralização e modelo sistêmico: o caso da vigilância sanitária. Ciênc Saúde Coletiva 2010; 15(Supl. 3):3318-3320.

6. Souza LEPF. A vigilância sanitária e a mudança do modelo de atenção à saúde. Ciênc Saúde Coletiva 2010; 15 (Supl. 3):3320-3322.

7. Souza MS, Medeiros LB, Saccol ALF. Implantação das boas práticas em UAN. Alim Nutr. 2013; 24(2):203-207.

8. Brasil. Agência Nacional de Vigilância Sanitária. Cartilha de vigilância sanitária: boas práticas para serviços de alimentação. $3^{\text {a }}$ ed. Brasília: ANVISA; 2004.

9. Prefeitura do Rio de Janeiro. Subsecretaria de Vigilância. Fiscalização Sanitária e Controle de Zoonoses. Roteiro para elaboração do manual de boas práticas [Internet]. Disponível em: http:// www.rio.rj.gov.br/web/vigilanciasanitaria/exibeconteudo?id=5116437

10. Kraemer FB, Saddy MA, Garcia SRMC. Guia de elaboração do manual de boas práticas para manipulação de alimentos 2007. Rio de Janeiro: Conselho Regional de Nutricionistas - $4^{\circ}$ Região CRN-4; 2007.

11. São Paulo. Conselho Regional de Nutricionistas - $3^{\circ}$ Região - CRN-3. Manual de boas práticas, modelo básico para orientação dos profissionais [Internet]. Núcleo Técnico do Conselho Regional de Nutricionistas. Disponível em: http://crn3.org.br/Duvidas/AtuacaoProfissional.

12. Loopstra R, Tarasuk V. The relationship between food banks and household food insecurity among low-income Toronto families. Canadian Public Policy 2012; 38(4):497-514.

13. Tarasuk V, Eakin JM. Charitable food assistance as symbolic gesture: an ethnographic study of food banks in Ontario. Soc Sci Med. 2003; 56:1505-1515.

14. Brasil. Ministério do Desenvolvimento Social e Agrário. Segurança Alimentar. Notícias. Bancos de alimentos combatem o desperdício. Disponível em: http://mds.gov.br/area-de-imprensa/ noticias/2015/junho/bancos-de-alimentos-combatem-desperdicio 
15. Brasil. Conselho Nacional de Segurança Alimentar e Nutricional. A segurança alimentar e nutricional e o direito humano à alimentação adequada no Brasil: indicadores e monitoramento da Constituição de 1988 aos dias atuais. Brasília: CONSEA; 2010.

16. Soares AG, Oliveira AGM, Fonseca MJO, Freire Júnior M. Boas práticas de manipulação em bancos de alimentos. Rio de Janeiro: Embrapa Agroindústrias de Alimentos; 2006.

17. Silva LC, Santos DB, São José JFB, Silva EMM. Boas práticas na manipulação de alimentos em Unidades de Alimentação e Nutrição. Demetra 2015; 10(4):797-820.

18. Amorim STSP, Moreira H, Carraro TE. A formação de pediatras e nutricionistas: a dimensão humana. Rev Nutr. 2001; 14(2):111-118.

19. Serviço Social do Comércio. Administração Regional Paraná. Direção de Saúde e Ação Social. Gerência de Saúde. Coordenação Estadual do Programa Mesa Brasil. Check List do Banco de Alimentos do Programa Mesa Brasil Sesc Paraná: Edição 2013; Curitiba: SESC; 2013.

20. Brasil. Ministério da Saúde. Portaria no 1.428, de 26 de novembro de 1993. Determina que os estabelecimentos relacionados à área de alimentos, adotem, sob responsabilidade técnica, suas próprias Boas Práticas de Produção e/ou Prestação de serviços, seus Programas de Qualidade, e atendam aos Padrões de Identidade e Qualidade (PIQ's) para produtos e serviços na área de alimentos. Diário Oficial da União 02 dez. 1993.

21. Brasil. Ministério da Saúde. Secretaria de Vigilância Sanitária. Agência Nacional de Vigilância Sanitária. Resolução RDC no 275, de 21 de outubro de 2002. Dispõe sobre o Regulamento Técnico de Procedimentos Operacionais Padronizados aplicados aos Estabelecimentos Produtores/ Industrializadores de Alimentos e a Lista de Verificação das Boas Práticas de Fabricação em Estabelecimentos Produtores/Industrializadores de Alimentos. Diário Oficial da União 23 out. 2003.

22. Brasil. Ministério da Saúde. Secretaria de Vigilância Sanitária. Agência Nacional de Vigilância Sanitária. Resolução RDC no 216, de 15 de setembro de 2004. Dispõe sobre regulamento técnico de boas práticas para serviços de alimentação. Diário Oficial da União 16 set. 2004.

23. Schottz V, Cintrão RP, Santos RM. Convergências entre a Política Nacional de SAN e a Construção de Normas Sanitárias para Produtos da Agricultura Familiar. Vig Sanit Debate 2014; 2(04):115-123.

24. Organização Pan-Americana da Saúde. Codex alimentarius: higiene dos alimentos. $3^{\circ}$ ed. Brasília: OPAS; 2006. Textos Básicos.

25. Serviço Social do Comércio. Modalidades operacionais [Internet]. Disponível em: http://www.sesc. com.br/mesabrasil/modalidades.html.

26. Cruz FT. Qualidade e boas práticas de fabricação em um contexto de agroindústrias rurais de pequeno porte. [dissertação]. [Florianópolis]: Universidade Federal de Santa Catarina, Centro de Ciências Agrárias; 2007.

Recebido: 19/05/2016

Revisado: 29/01/2017

Aceito: 03/04/2017 
